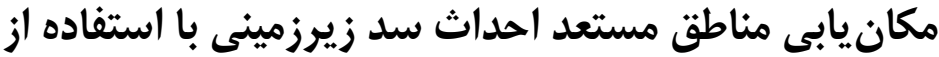 منطق فازى و بولين در مناطق مركزى استان ارئ اردبيل
}

\author{
اباذر اسمعلى '، محمد كَلشن 'َ و كيوان خرمى \\ 1- دانشيار، دانشًاه محقق اردبيلى، دانشكده كشاورزى و منابع طبيعى، اردبيل (نويسنده مسوول: abazar.esmali@gmail.com)

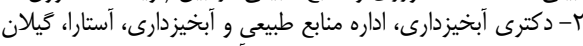

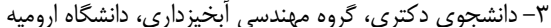

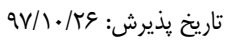 \\ تاريخ دريافت: (

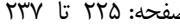

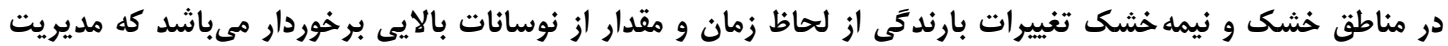

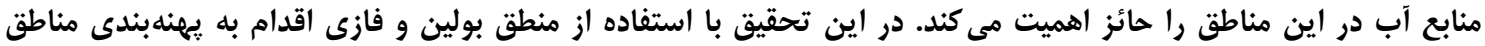

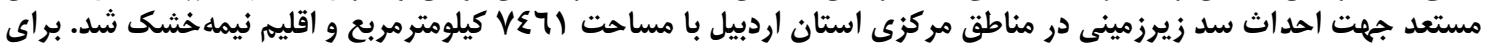

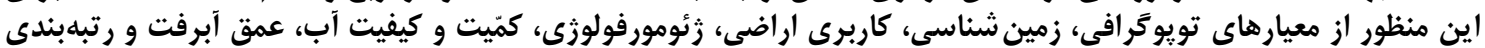

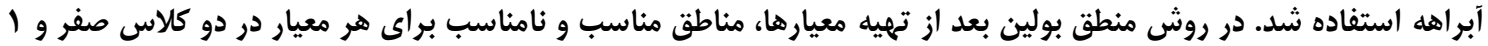

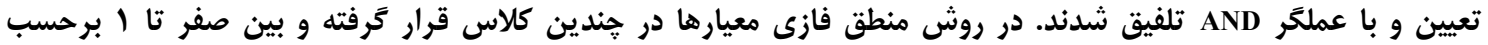

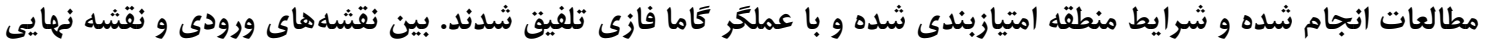

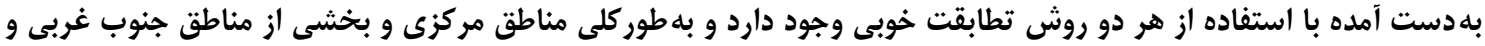

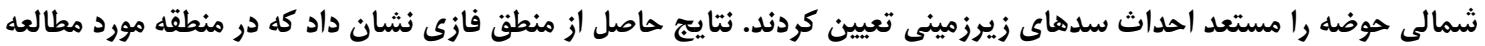

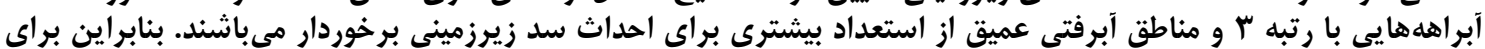

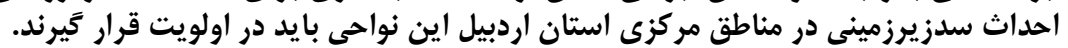

وازههاى كليدى: آبرفت، عوامل هيدرولوزيكى، زمينشناسى، منابع آب

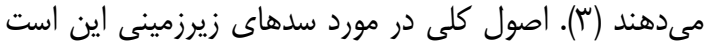

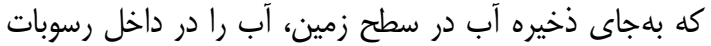

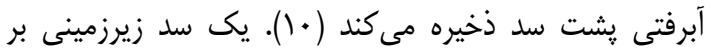

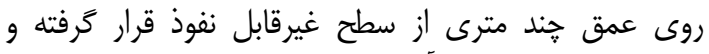

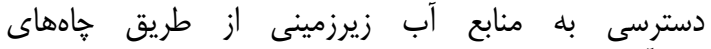

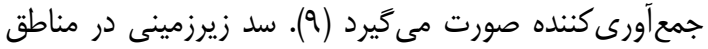

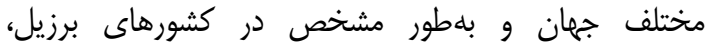

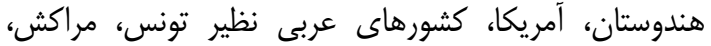

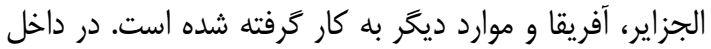

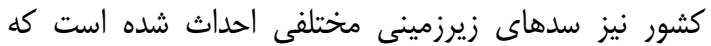

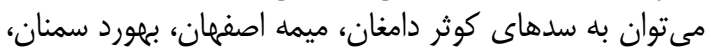

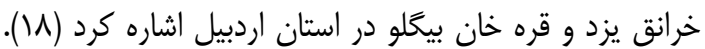

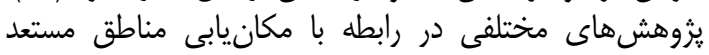

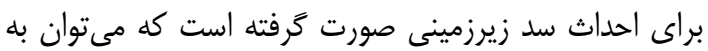

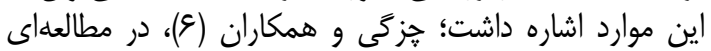

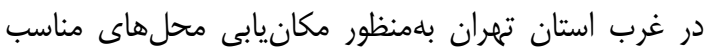

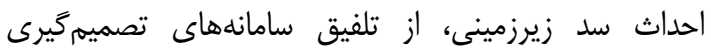

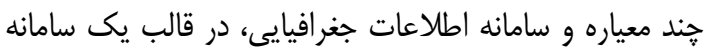

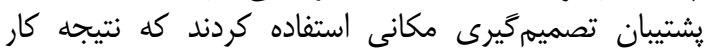

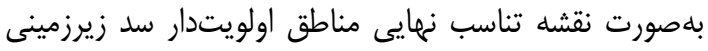

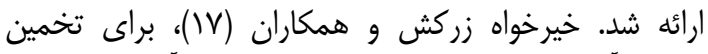

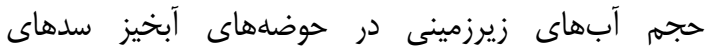

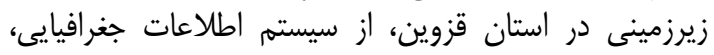

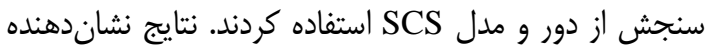
برترى روشهاى نوين برآورد رواناب و دقت سيسته اطلاعات
راهكارهاى مقابله با كم آبى در دو استراتثى مديريت

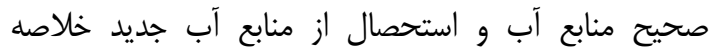

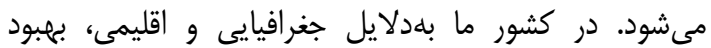

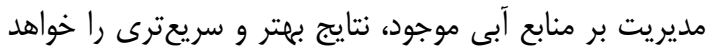

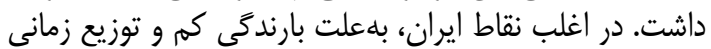

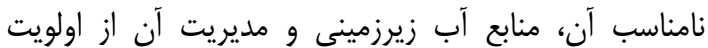

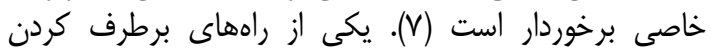

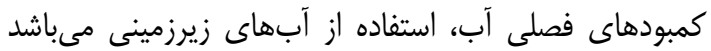

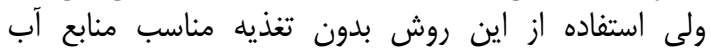

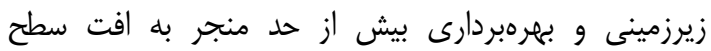

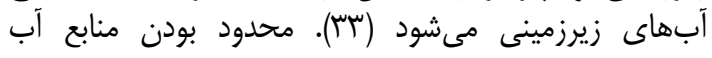

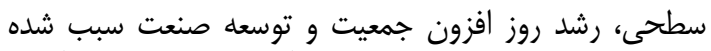

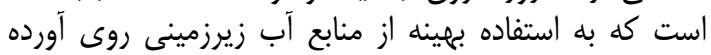

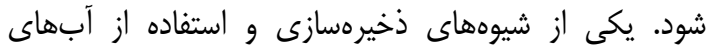

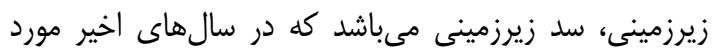

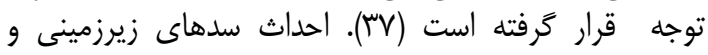

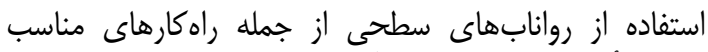

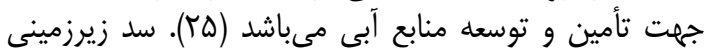

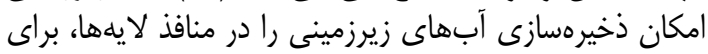

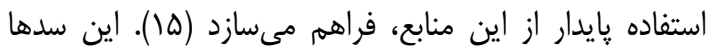

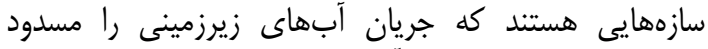

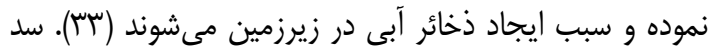

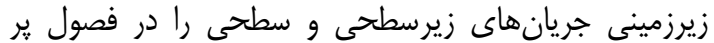
باران جمعآورى كرده و در مواقع كمآبى در دسترس رئ دئ قرار 
ارتفاع و شبكه آبراهه منطقه مطالعاتى را بهدست آورده و نتايج

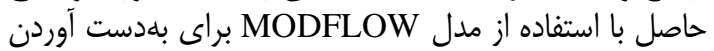

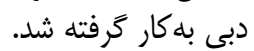

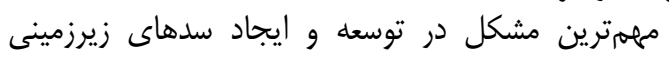

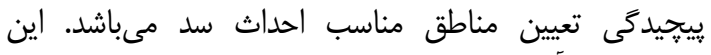

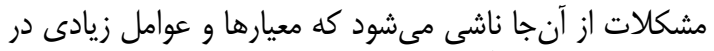

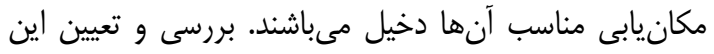

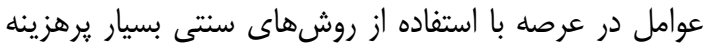

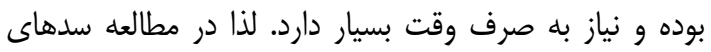

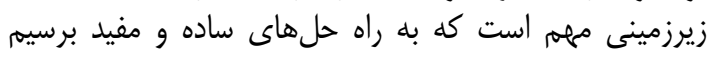

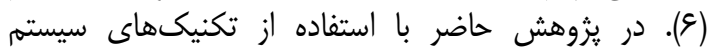

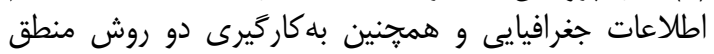

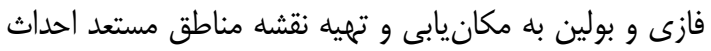

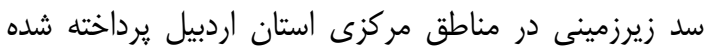

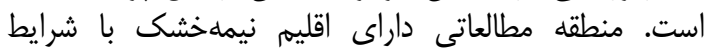

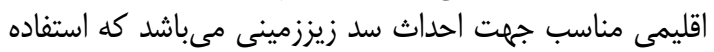

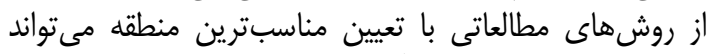

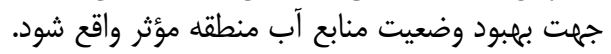

\section{مواد و روشها منطقه مورد مطالعه}

حوضه مورد مطالعه (مناطق مركزى استان اردبيل)، جزو إنها

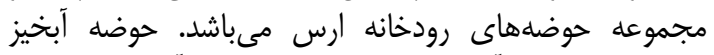

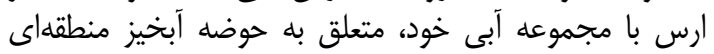

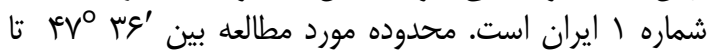

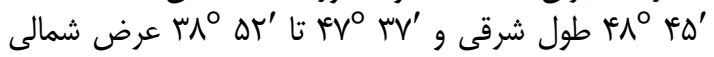

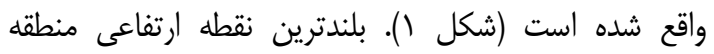

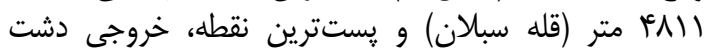

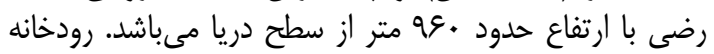

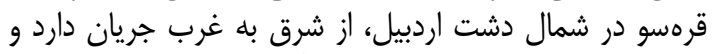

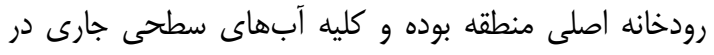

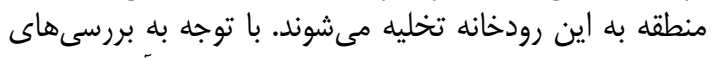

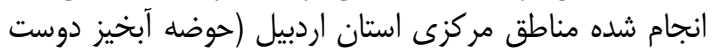

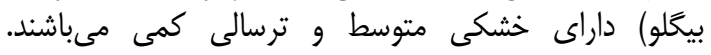

جغرافيايى مىباشد. همجنين استفاده از روشهاى نوين باعث

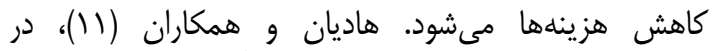

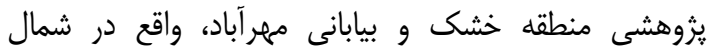

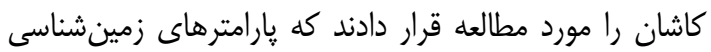

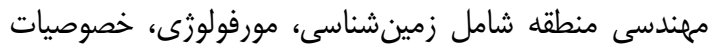

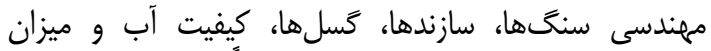

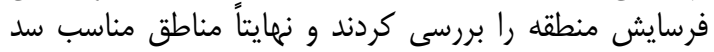

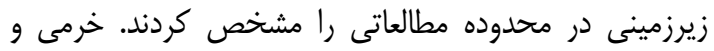

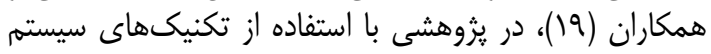

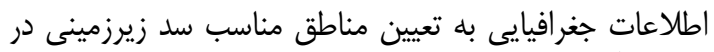

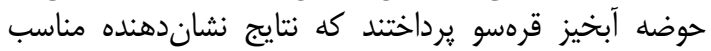

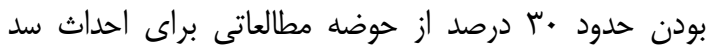
زيرزمينى بودند.

در اتيويى تحقيقى توسط شنكوت (اسّ)، مبنى بر جمع إنى

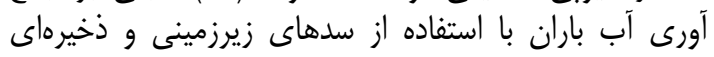

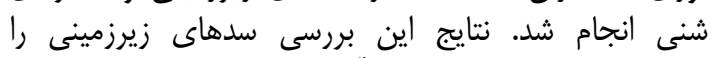

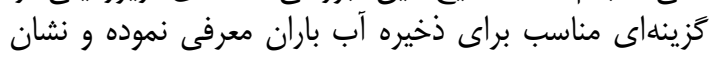

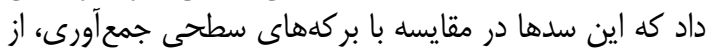

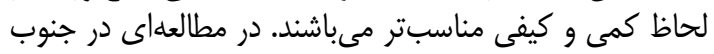

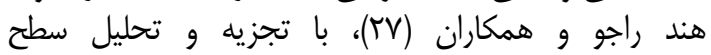

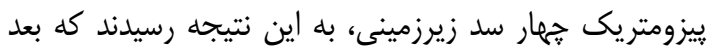

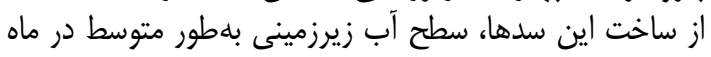

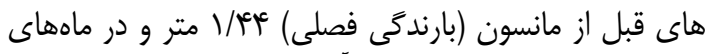

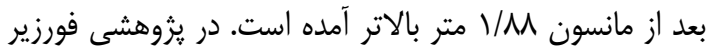

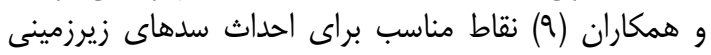

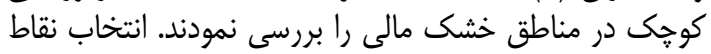

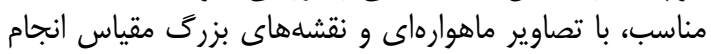

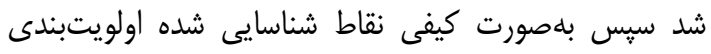

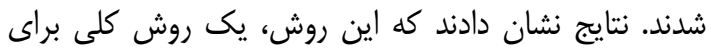

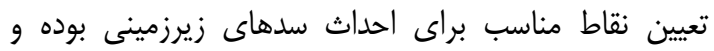

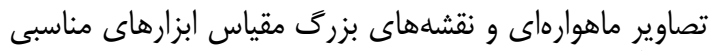

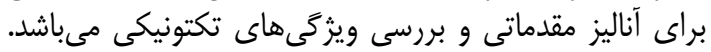

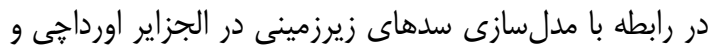

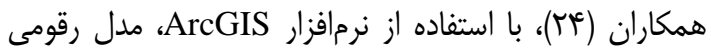

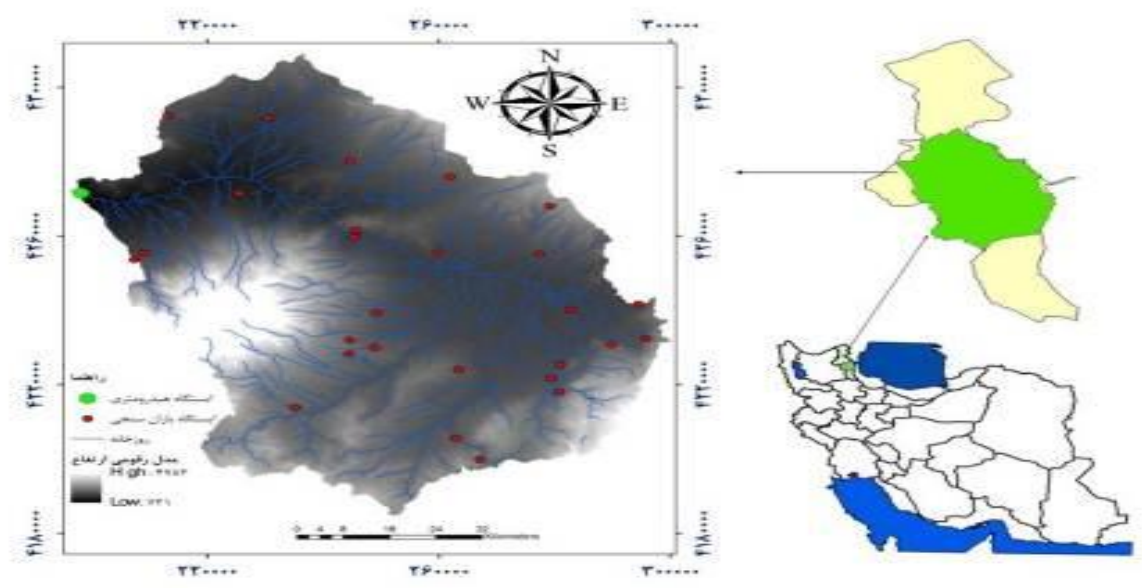

شكل 1- موقعيت محدوده مطالعاتى در ايران

Figure 1. Location of the study area in Iran 
يزوهش با استفاده از تكنيكهاى سيستم اطلاعات زمين

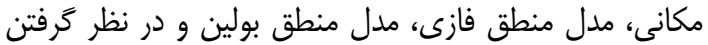

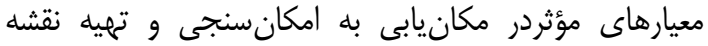

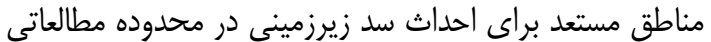

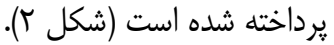

يهنهبندى مناطق مستعد براى مديريت و دستيابى به

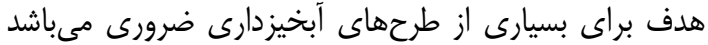

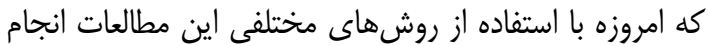

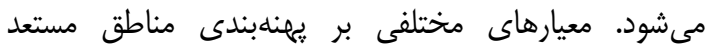

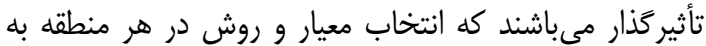

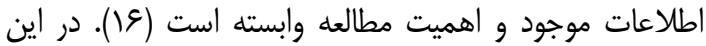

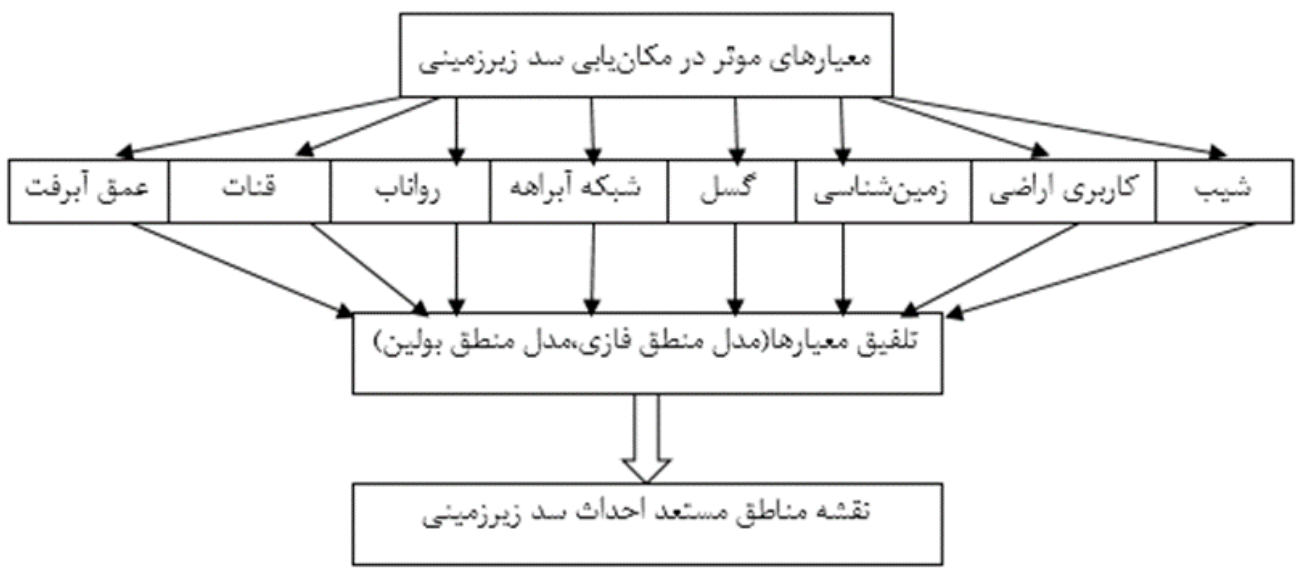

شكل r- معيارهاى موثر در تعيين مناطق مناسب سد زيرزمينى

Figure 2. Effective criteria in determining the suitable areas for underground dam

بلددليل قرار داشتن در ارتفاعات و شيبهاى بالاتر و همهنين

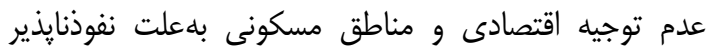

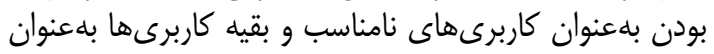
مناطق مناسب در نظر گرفته شدند. زمينشناسى و تمسل

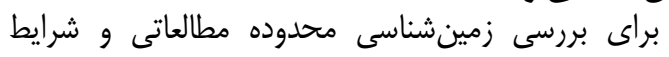

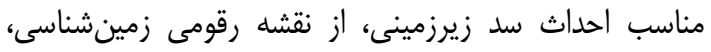

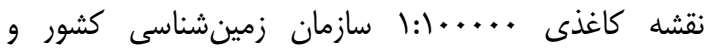

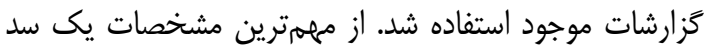

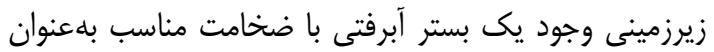

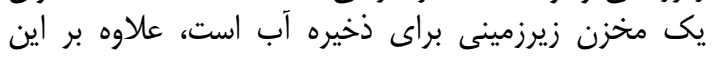

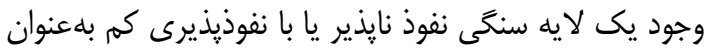

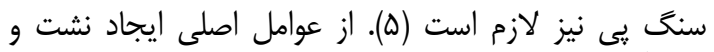

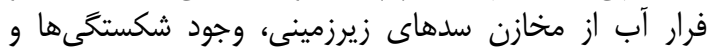

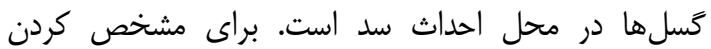

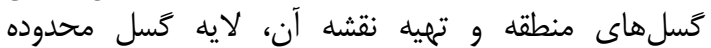

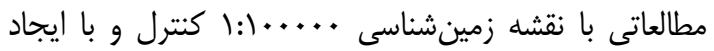

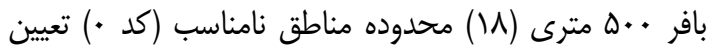

$$
\text { شبكه آبراهله و رواناب }
$$

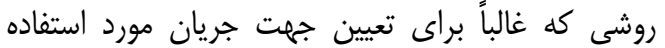

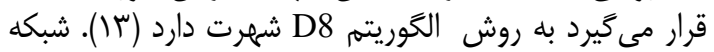

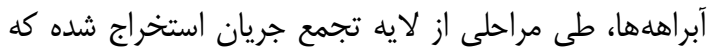

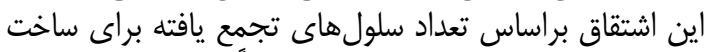

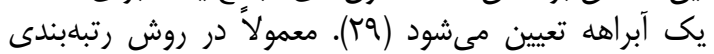

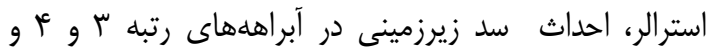

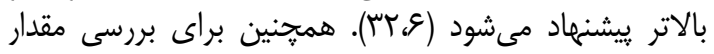

شيب آن جا كه شيب سطح إستابى و در نتيجه ميزان جريان

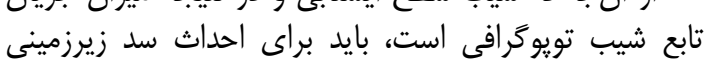

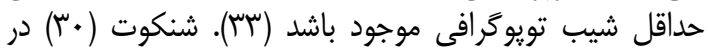

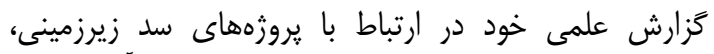

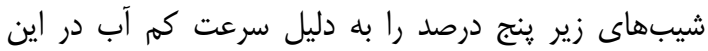

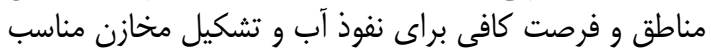

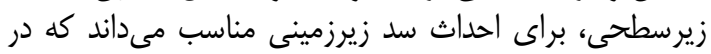

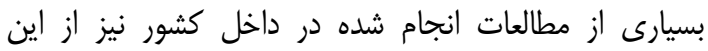

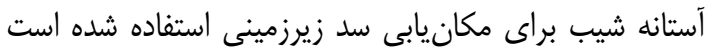

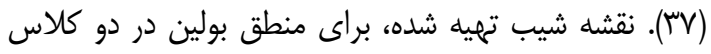

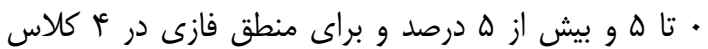

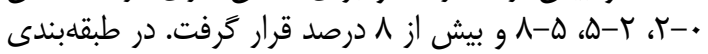

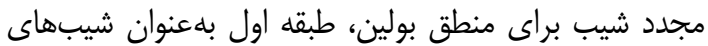

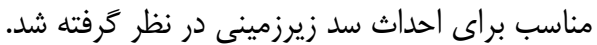

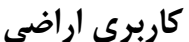

اين نوع سدها منجر به تغيير كاربرى اراضى و اكوسيستم

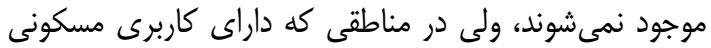

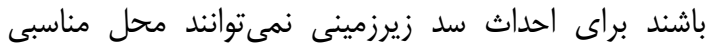

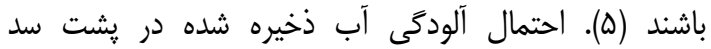

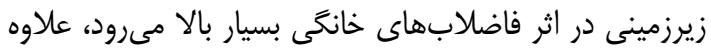

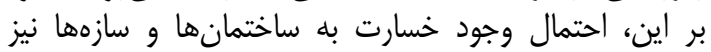

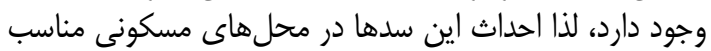

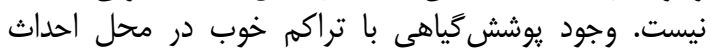

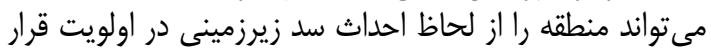

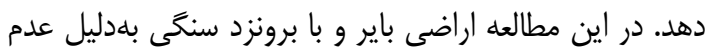

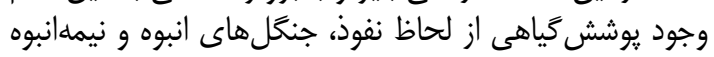


سلولى تبديل شدند. براى توليد نقشه نهايى در اين مدل

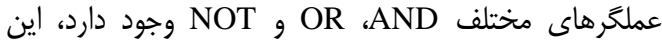

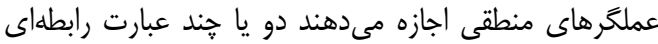

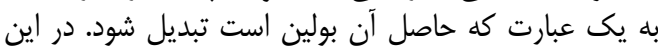
تحقيق با توجه به هدف از عملكًر AND استفاده شد.

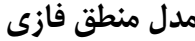

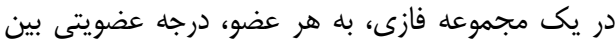

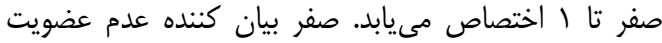

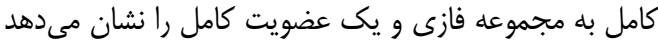

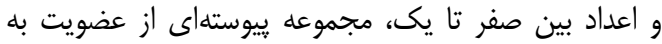

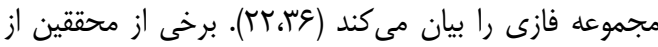

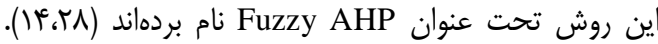

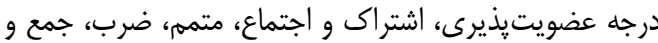

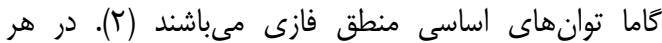

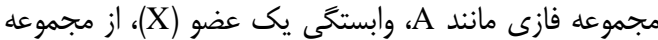

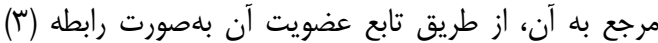

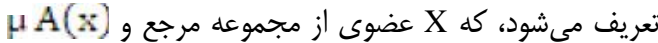

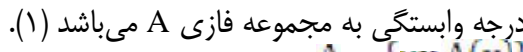
$A=\{\mu x A(x)\}$

رابطه (广) بانه با توجه به نتايج مطالعات انجام شده در رابطه با كارآيى دري

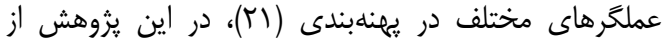

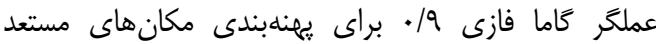

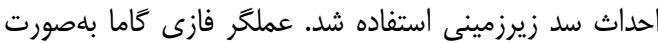
رابطه زير (أ) تعريف مى شود:

رابطه (f)

\section{$\mu=(\mu \text { fuzzy sum })^{y} \times(\mu \text { fuzzy product })^{1-s}$}

مقدار Y در بازه بين صفر تا يك قرار دارد كه انتخاب آكًاهانه

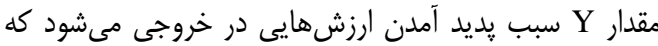

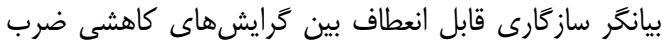

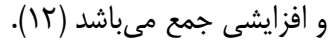

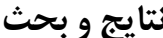

در اين مبحث با توجه به دادهها و روشهاى موري مورد

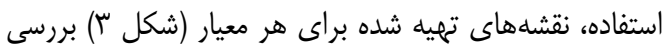

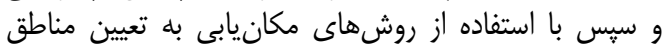
مناسب احداث سد زيرزمينى برداخته مى شيود.

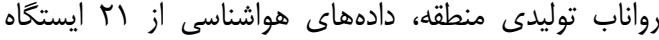

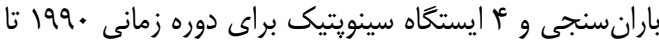

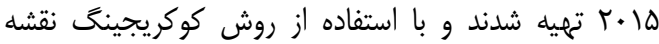

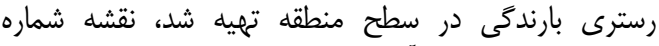

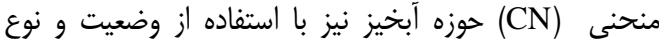

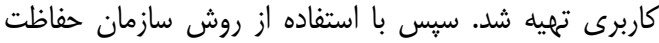
آب و خاك (SCS)، روابط (I) و (Y) ارتفاع استفاده شد.

$R=\frac{(P-0.2 S)^{2}}{(P+0.8 S)}$

رابطه (1)

$\mathrm{S}=25.4\left(\frac{1000}{\mathrm{CN}}-10\right)$

رابطه (T)

در اين روابط R مقدار رواناب، P مقدار بارندكى و S مقدار

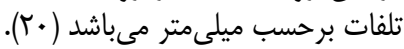
قنوات، جاهاها، آبرفت

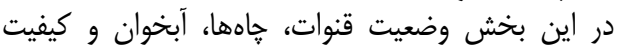

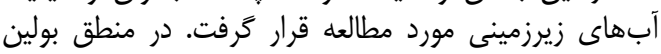

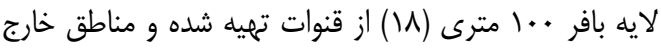

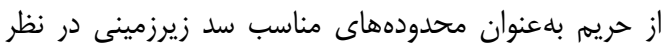

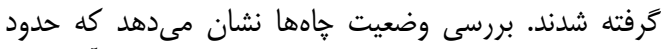

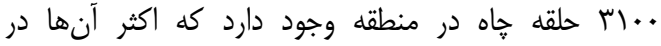

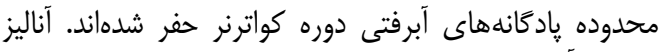

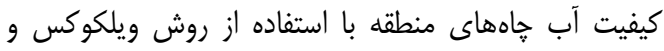

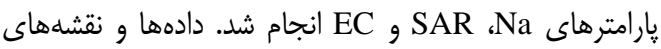

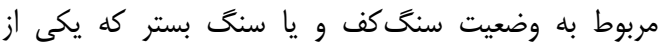

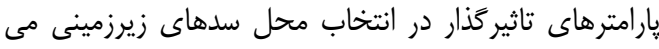

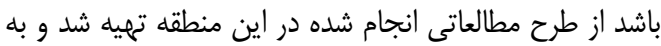

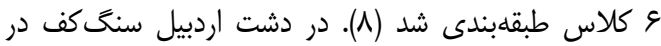

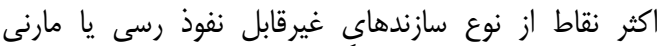
مى باشد، اين رسوبات تقريباً در تمام منطقه كَّترش دارند

مدل منطق بولين

منطق بولين بهدليل سادگى منطق و محاسبات آن آن اجراى

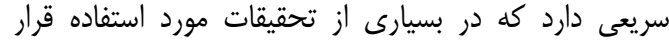

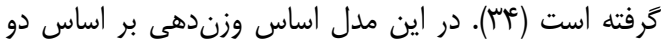

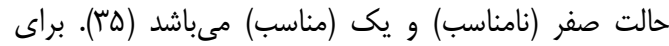

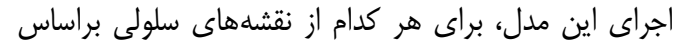

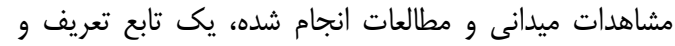

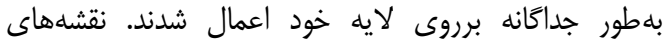

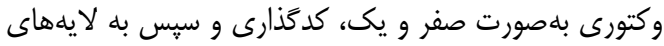


rrq يثوهشنامه مديريت حوزه آبخيز سال دهم/ شماره •r/ يإييز و زمستان ـوسا .
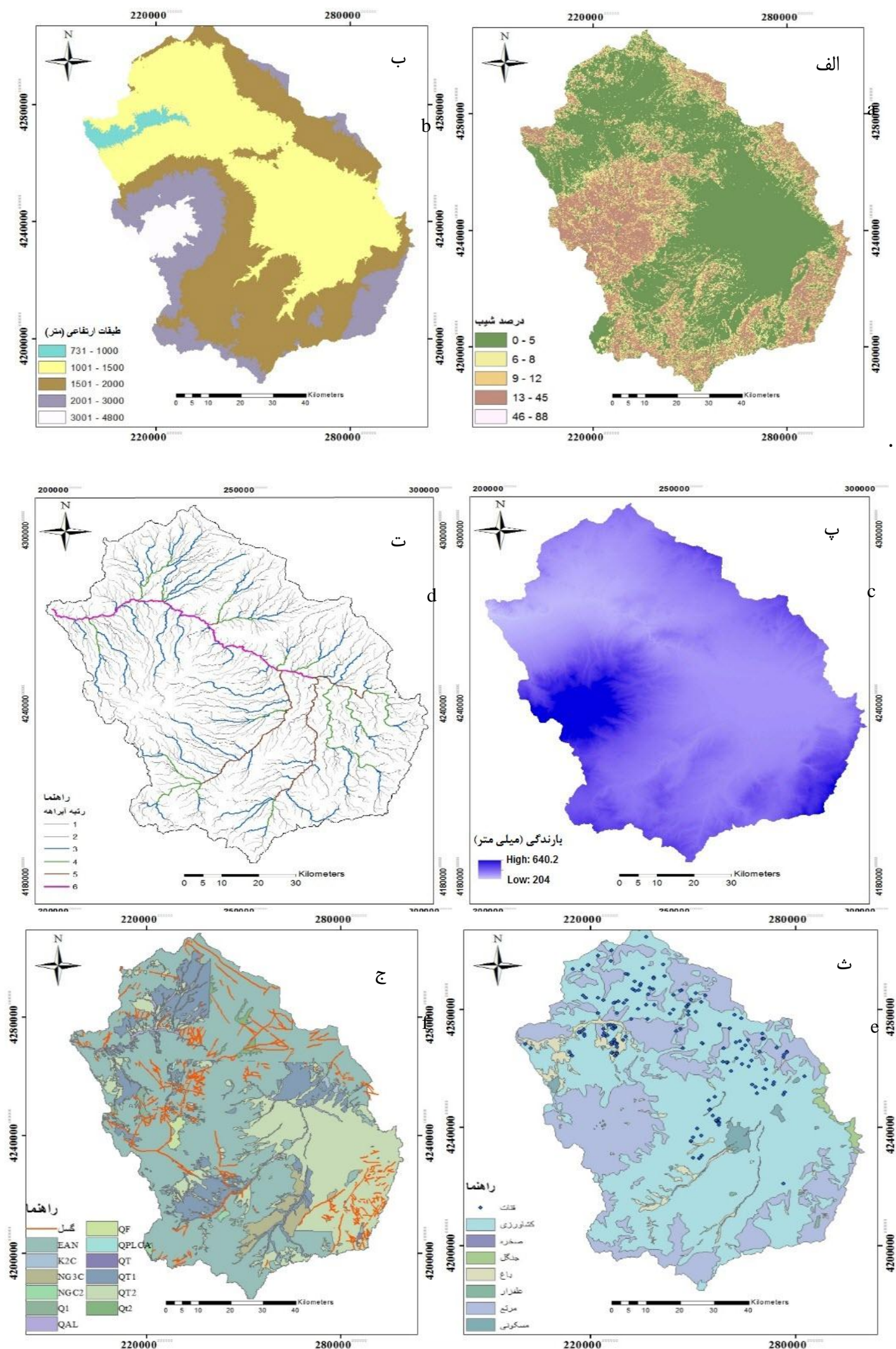

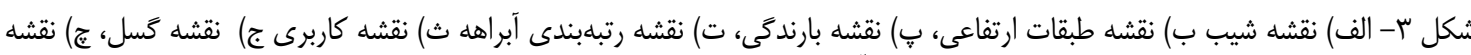

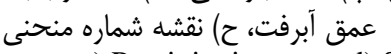

Figure 3. a) Slope map, b) Altitude classes map, c) Precipitation map, d) Stream ordering map, e) Land use map, f) Fault map, g) Depth of alluvium map, h) Curve number map 

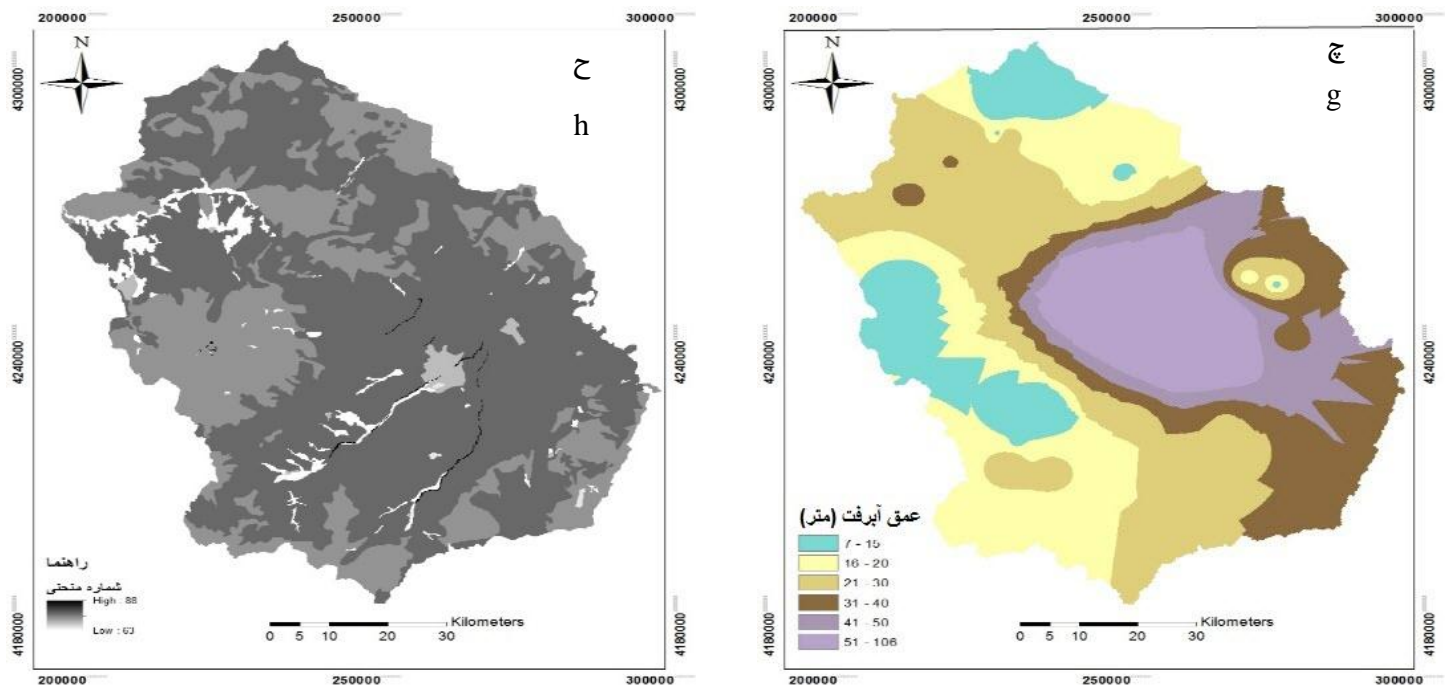

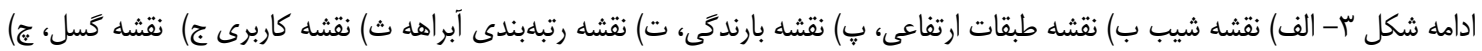

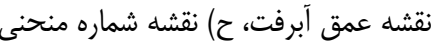

Continued Figure 3. a) Slope map, b) Altitude classes map, c) Precipitation map, d) Stream ordering map, e) Land use map, f) Fault map, g) Depth of alluvium map, h) Curve number map

درصد از كل حوضه را تشكيل داده و مناسب براى احداث سد بردي

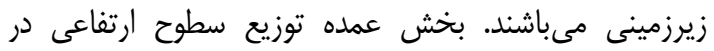

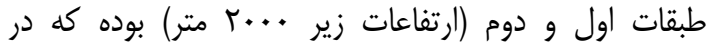

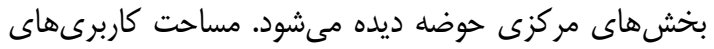

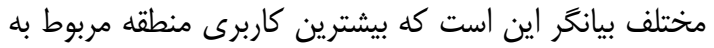

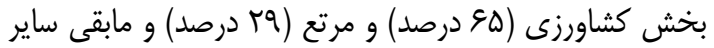

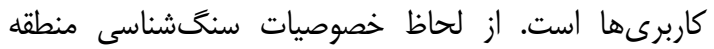

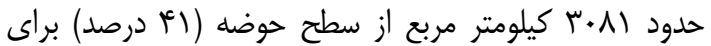

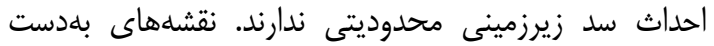

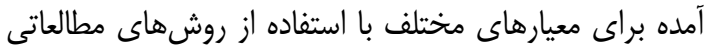
در شكل ه نشان داده شده است.
بررسى كيفيت بهاى زيرزمينى منطقه نشان ميدهد كه

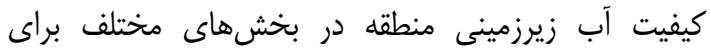

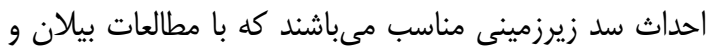

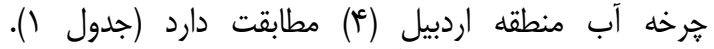

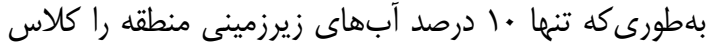

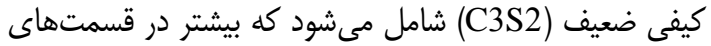

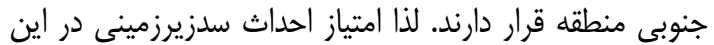

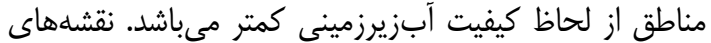

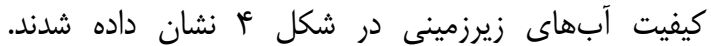

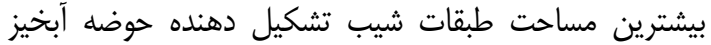

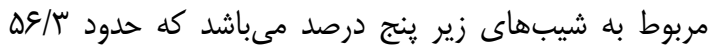
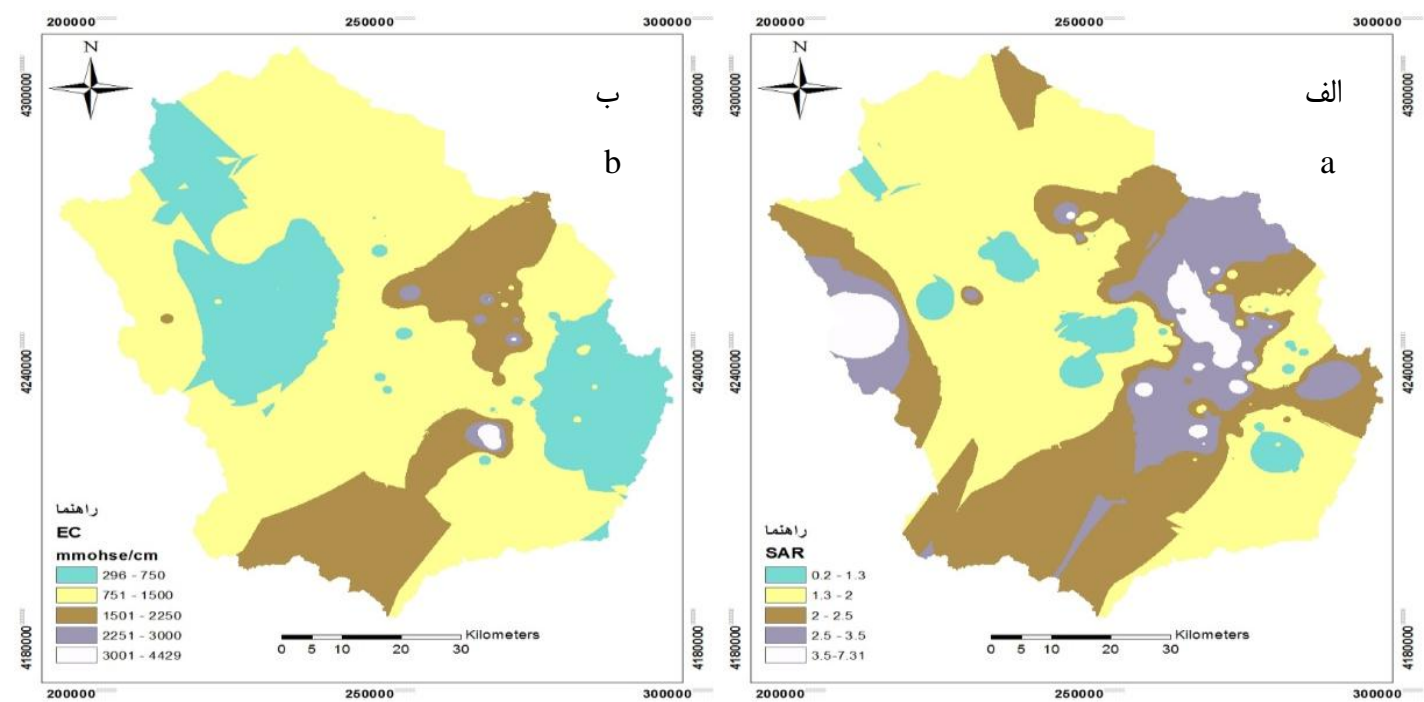

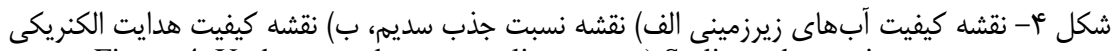

Figure 4. Underground water quality map, a) Sodium abstraction rate map 
Table 1. Qualitative status of groundwater using Wilcox diagram

جدول ا- وضعيت كيفى آبهاى زيرزمينى با استفاده از دياگر ام ويلكوكس

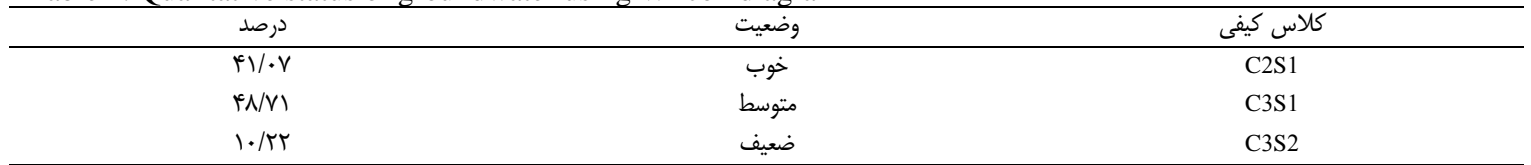
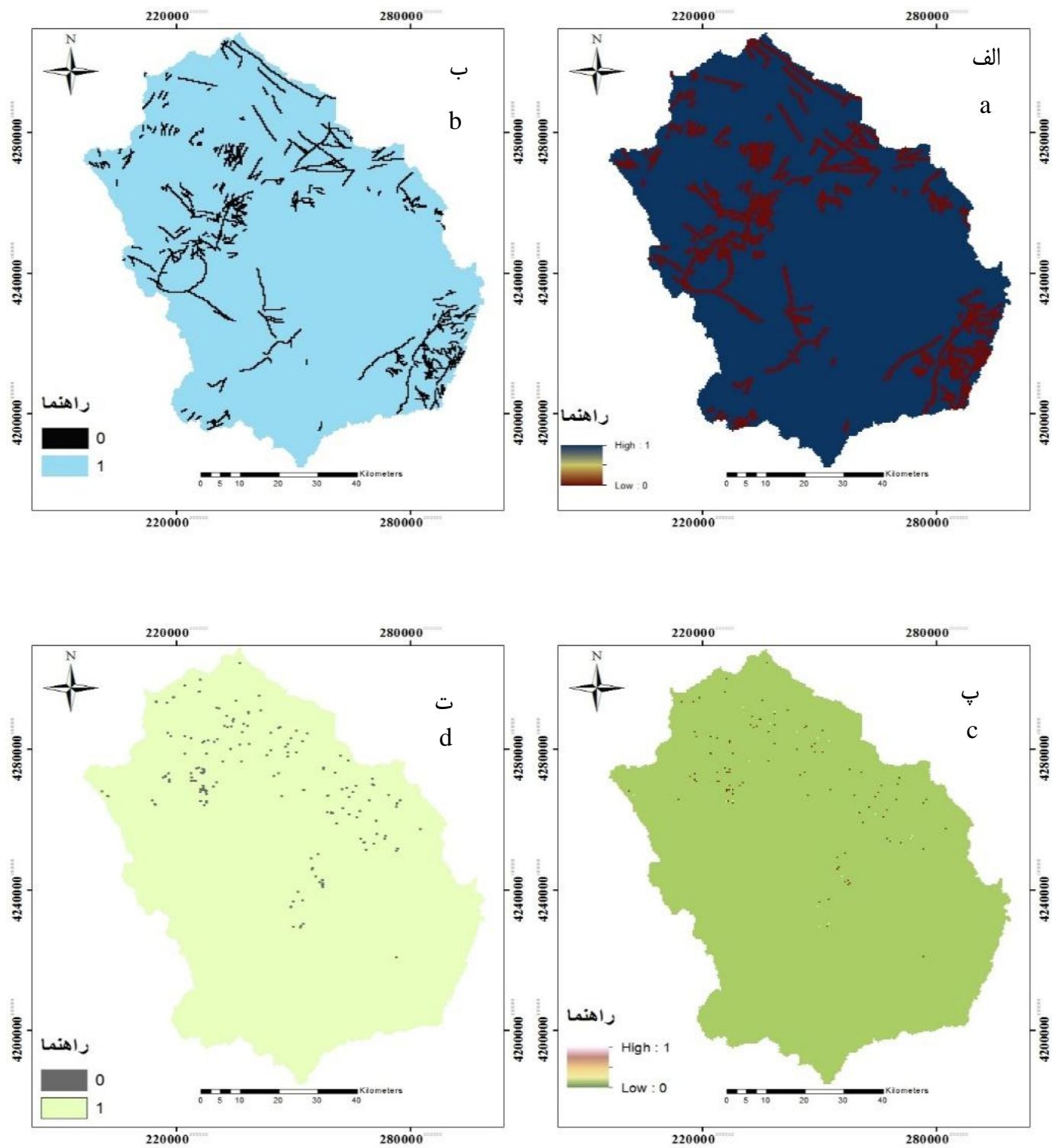

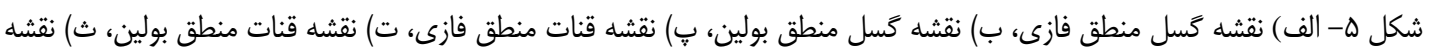

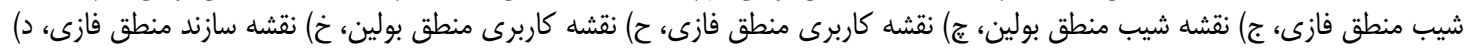

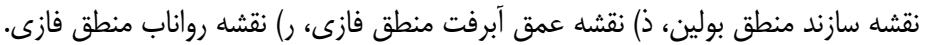

Continued Figure 5. a) Fuzzy logic fault map, b) Boolean logic fault map, c) Fuzzy logic aqueduct map, d) Boolean logic aqueduct map, e) Fuzzy logic slope map, f) Boolean logic slope map, g) Fuzzy logic land use map, h) Boolean logic land use map, i) Fuzzy logic formation map, j) Boolean logic geological formations map, k) Fuzzy logic 

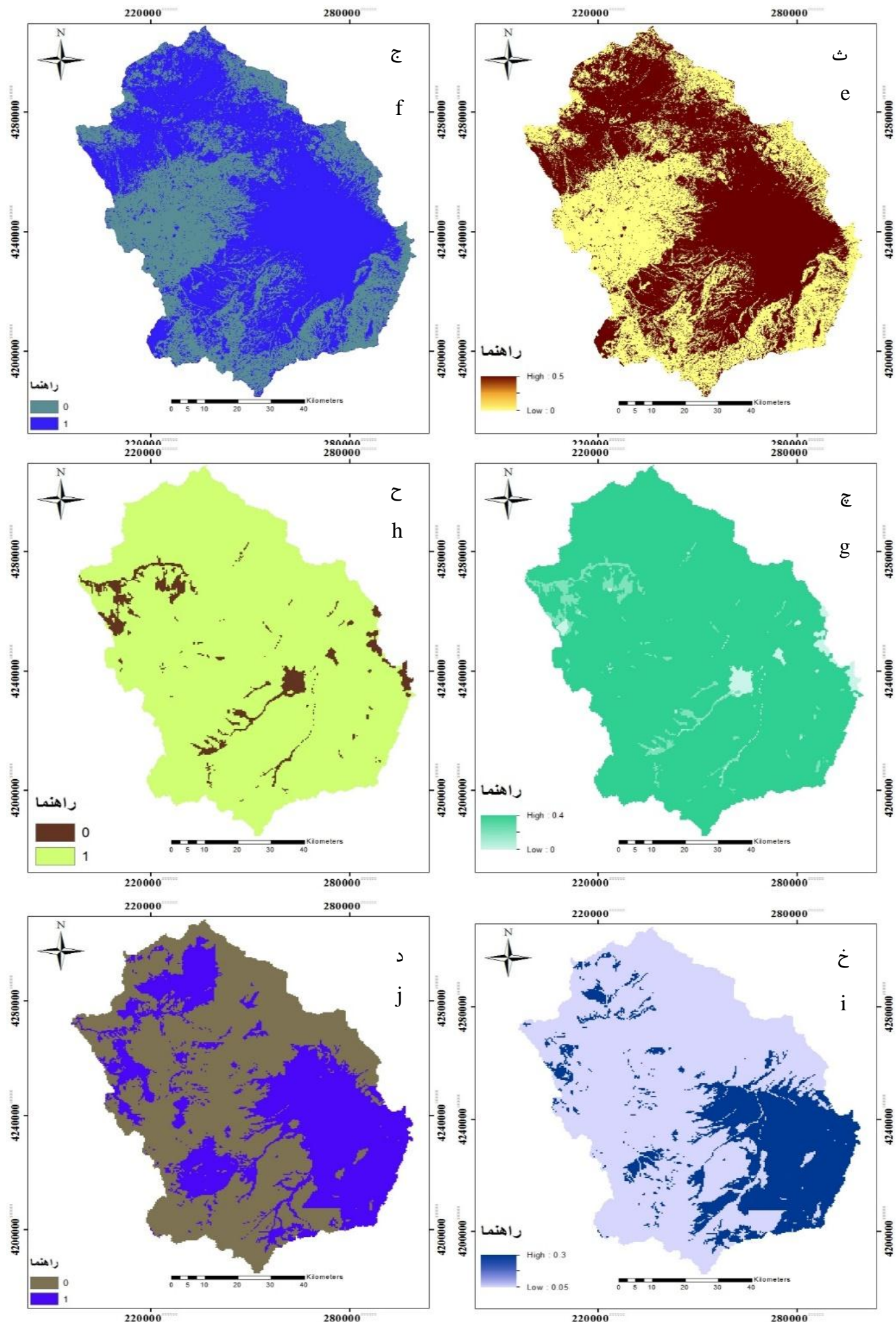

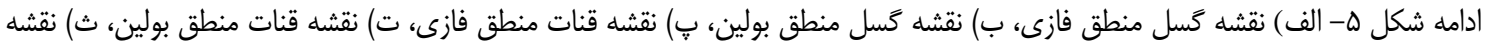

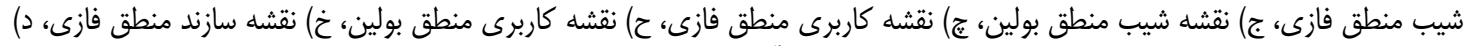

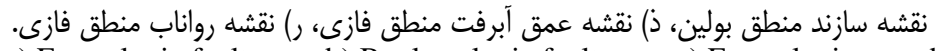

Continued Figure 5. a) Fuzzy logic fault map, b) Boolean logic fault map, c) Fuzzy logic aqueduct map, d) Boolean logic aqueduct map, e) Fuzzy logic slope map, f) Boolean logic slope map, g) Fuzzy logic land use map, h) Boolean logic land use map, i) Fuzzy logic formation map, j) Boolean logic geological formations map, k) Fuzzy logic 


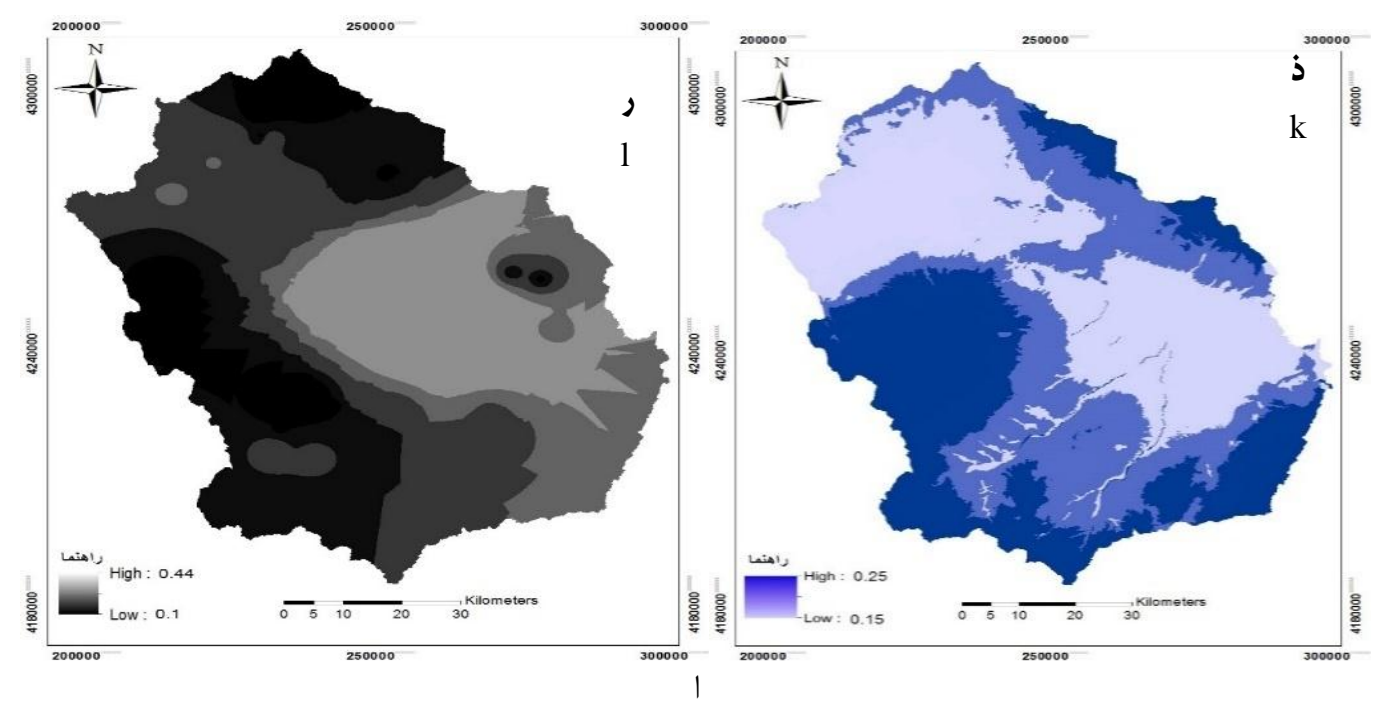

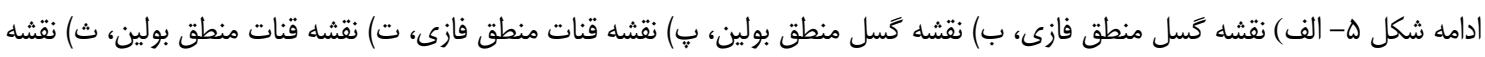

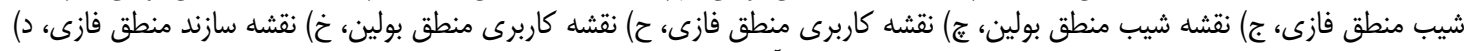

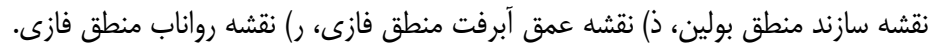

Continued Figure 5. a) Fuzzy logic fault map, b) Boolean logic fault map, c) Fuzzy logic aqueduct map, d) Boolean logic aqueduct map, e) Fuzzy logic slope map, f) Boolean logic slope map, g) Fuzzy logic land use map, h) Boolean logic land use map, i) Fuzzy logic formation map, j) Boolean logic geological formations map, k) Fuzzy logic alluvium depth map, 1) Fuzzy logic runoff map

كه با كد صفر معين شدهاند بهعنوان بخش مأى نامناسب در

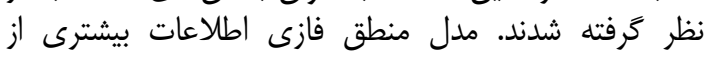

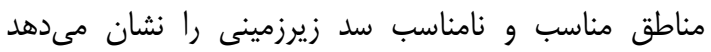

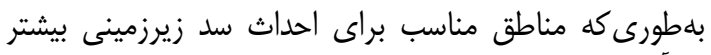

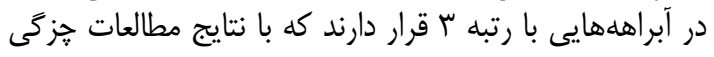

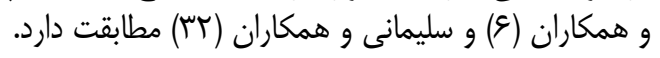

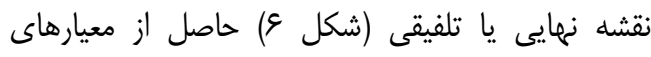

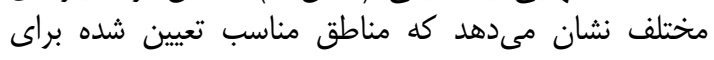

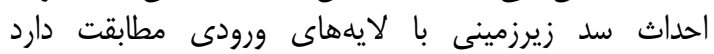

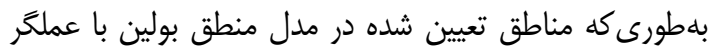
AND از لحاظ احداث ندارد و با كد ا مشخص شرار دارد است و مناطقى
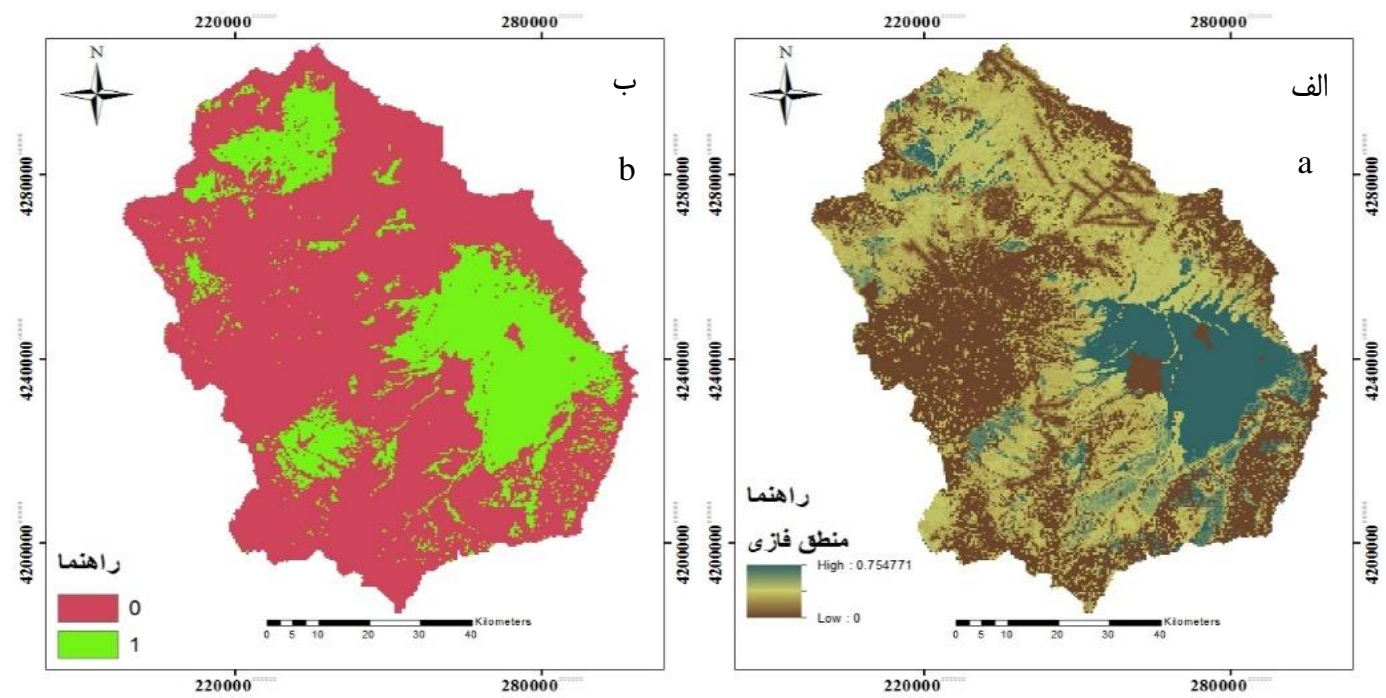

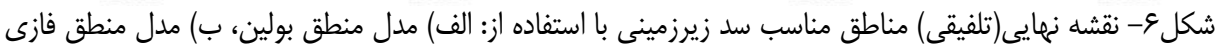

Figure 6. Final map (compilation) of the suitable areas for underground dam using: a) Boolean logic model, b) Fuzzy logic model

مىتوان با انتخاب تنكاههاى مناسب آب كشاورزى و مورد نياز

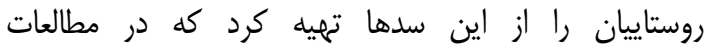
حاجى عزيزى و همكاران (TI) و بيرمرادى و همكاران (Tهان به به
با توجه به اين كه سدهاى زيرزمينى در مناطقى با يهنئه

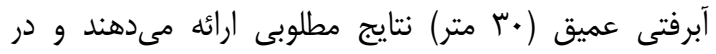

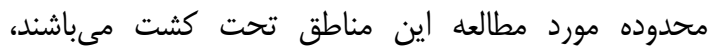


سازندهاى نفوذنايذير يا حساس به فرسايش و داراى املاح

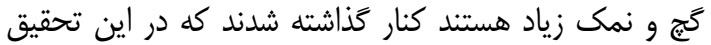

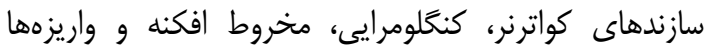

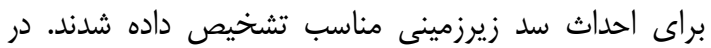

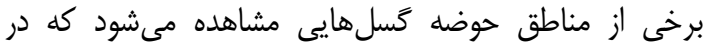

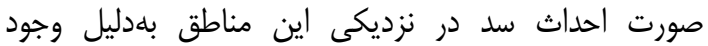

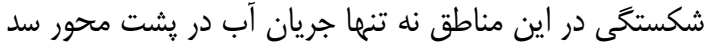

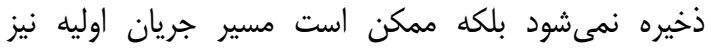

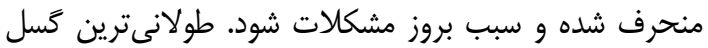

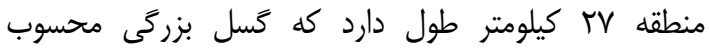

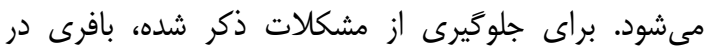

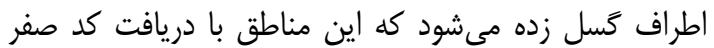

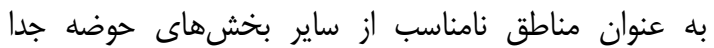

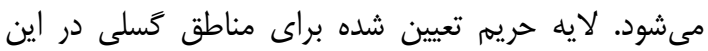

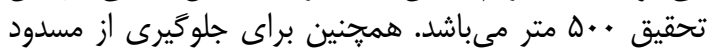

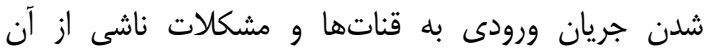

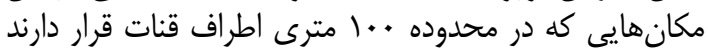

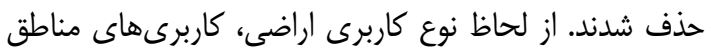

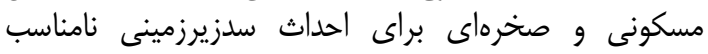

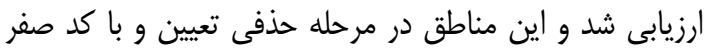

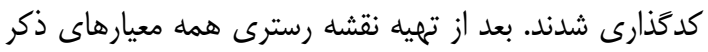

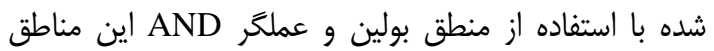

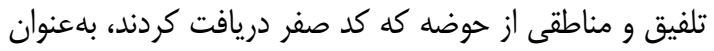

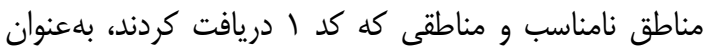

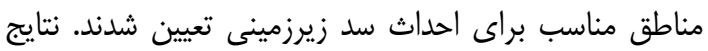

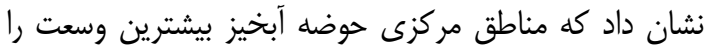

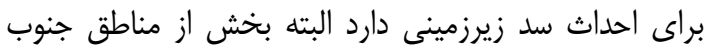

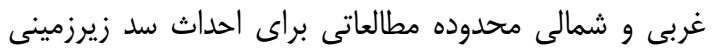

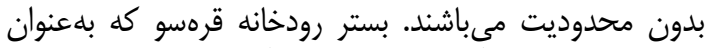

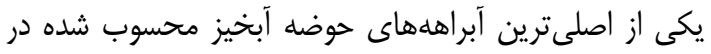

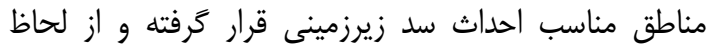

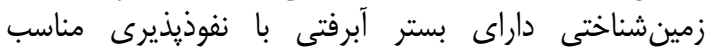

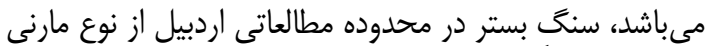

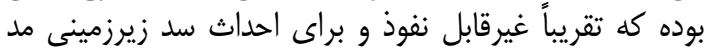

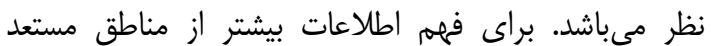

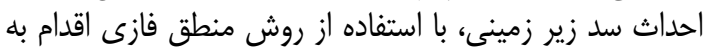

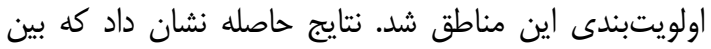

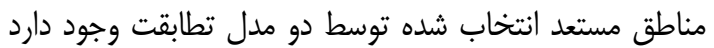

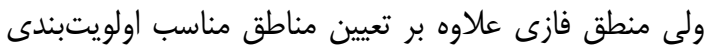

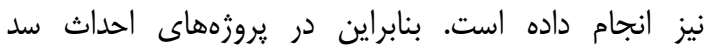

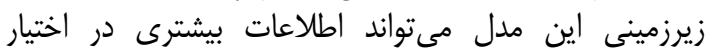

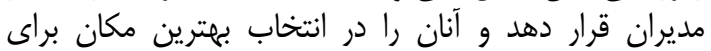
احداث سد زيرزمينى يارى نمايد.

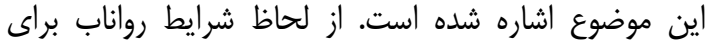

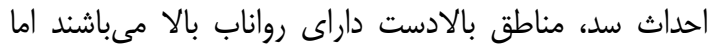

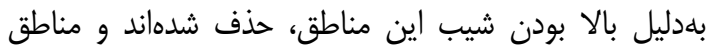

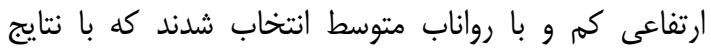

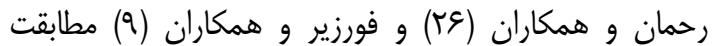

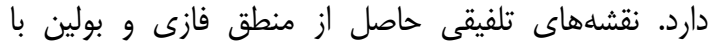

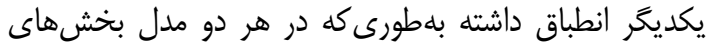

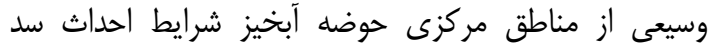

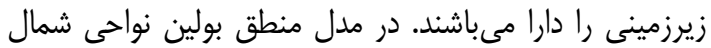

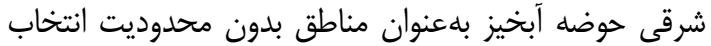

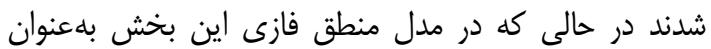

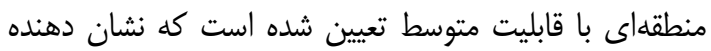

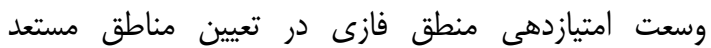

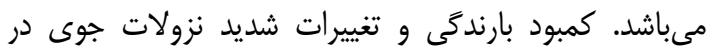

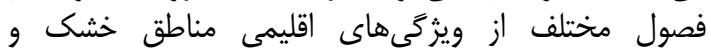

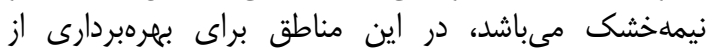

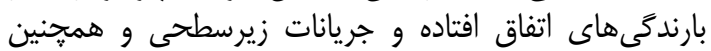

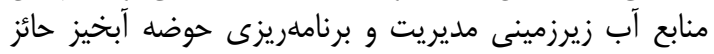

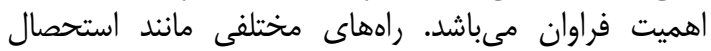

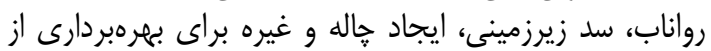

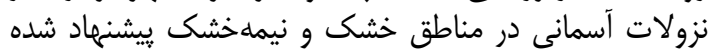

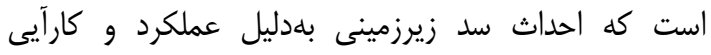

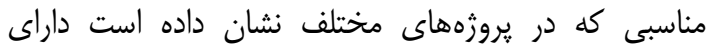

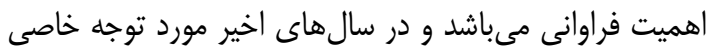

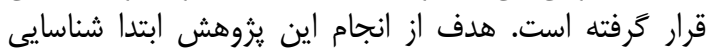

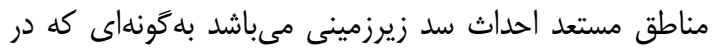

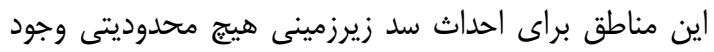

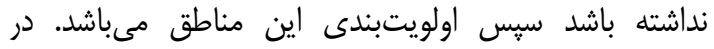

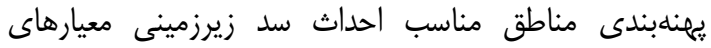

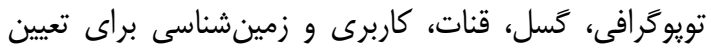

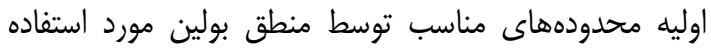

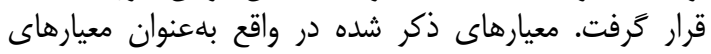

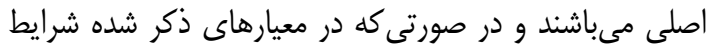

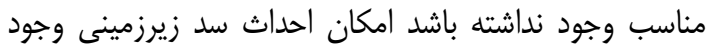
نخواهد داشت.

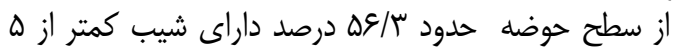

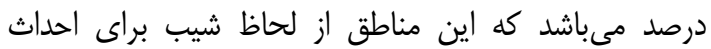

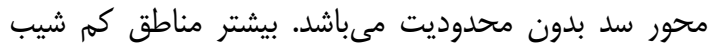

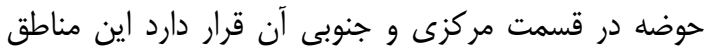

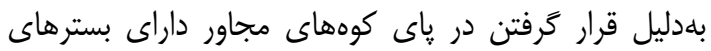

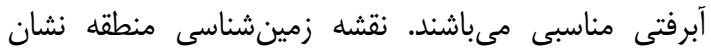

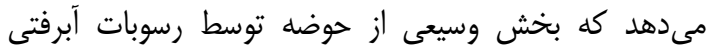

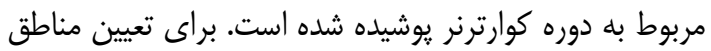

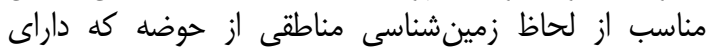


1. Abadinejad, M., M. Yemani, M. Mehran and S. Shadfar. 2007. Evaluation of Fuzzy logic operators' performance in determination of landslide capability. Watershed Management Science, (2): 39-44.

2. Abedini, M., B. Mirzakhani and A. Asghari. 2015. Geomorphologic zonation of land suitability in Arak city using fuzzy logic model, 5(18): 59-72, (In Persian).

3. Aminizadeh, B., Gh. Lashkaripur and M. Ghafori.2010. Monitoring methodology of underground dam (case study, Ravar underground dam). Irrigation and water, 1(2): 43-57 (In Persian).

4. Anonymous, 2005. Underground water reports, Discharge and water cycle studies. Gatreh Baran consulting engineers, $87 \mathrm{pp}$, (In Persian).

5. Ashghizadeh, M. and N. Nora. 2010. Determine the proper location of an underground dam on the aqueduct. Water and soil protection, 17(3): 45-64 (In Persian).

6. Chezghi, J., H.M. Moradi and M.M. Kheirkhah Zarkesh. 2012. Selection of suitable sites for underground dams using multi criteria decision making with an emphasis to water resources (Case Study: West of Tehran Province), Iranian Journal of Watershed Management Science and Engineering, 4(13): 65-68.

7. Davodi, M. 2004. Underground dams are an economical and effective way to manage and develop water resources. Publications of the institute for conservation and watershed management, (In Persian)

8. Esmali, A., M. Golshan and K. Khorrami. 2015. Mapping suitable areas for underground dam construction by using GIS (Case Study: Central areas of Ardabil province). Research Project, University of Mohaghegh Ardabili, 124 pp (In Persian).

9. Forzieri, G., M. Gardenti, F. Caparrini, and F. Castelli. 2008. A methodology for the pre-selection of suitable sites for surface and underground small dams, Journal of Physics and Chemistry of the Earth, 33(1-2): 74-85.

10. Garezi, R., A. Najafinejad, N. Nora, A. Dehghani and A. Filehkesh. 2012. Locating an underground dam with the help of GIS in the Sabzevar. $2^{\text {nd }}$ managing the environment conference. Tehran University, (In Persian).

11. Hadeian, F., Z. Shoaei, M. Kheikhah and A. Majidi. 2012. Surveying the factors for sit selection the underground dam using the GIS method and remote sensing. $31^{\text {th }}$ earth science conference, Geological Survey, Iran, 8 pp (In Persian).

12. Hajiazizi, S.H., M. Kheirkhah and A. Sharifi. 2011. Determining appropriate stream for underground dam construction with multi criteria decision making methods, remote sensing and GIS in natural resource, 2(2): 27-38.

13. Hoseinzadeh, R. and A. Bidkhory. 2008. Geography Information System (GIS), basics and tutorials for ArcGIS. Mashhad University Press, $250 \mathrm{pp}$ (In Persian).

14. Isaai, M., A. Kanani, M. Tootoonchi and H. Afzali. 2011. Intelligent timetable evaluation using fuzzy AHP, Expert Systems with Applications, 38(4): 3718-3723.

15. Ishida, S., T. Tsuchihara, S. Yoshimoto and M. Imaizumi. 2011. Sustainable use of groundwater with underground dams. Review, JARQ, 45(1): 51-61.

16. Jasmin I. and P. Mallikajuna. 2011. Satellite-based remote sensing and geographic information systems and their application in the assessment of groundwater potential, India, Hydrogeology, 19(4): 729-740.

17. Kheirkhah Zarkesh, M., T. Mohebi, Gh. Majidi and F. Asadeian. 2011. Estimation of underground water volume in underground drainage basins using GIS and RS. Water and recourse Lahijan unit, 4(4): 19-26 (In Persian).

18. Khorrami, K., Gh. Vahhabzadeh, K. Soleimani and R. Talaei. 2013. Selection sites of underground dam in the Gharesou watershed, Mater degree thesis, watershed management group, Sari Agricultural and Natural Resources University, 122 pp (In Persian).

19. Khorrami, K., Gh. Vahhabzadeh, K. Soleimani and R. Talaei. 2014. Determining the suitable areas of underground dam in Gharasou watershed, journal of Watershed Engineering and Management, 6(2): 139-154 (In Persian).

20. Mahdavi, M. 2007. Applied hydrology. Tehran university publication, $340 \mathrm{pp}$ (In Persian).

21. Naderi, F. 2012. Application of fuzzy logic in landslide hazard zonation in Chardavol Ilam watershed. Physical geography, 94: 74-85.

22. Nadun, S.N.E.M., I. Maarof, R. Ghazali, A.M. Samad and R. Adnan. 2010. Sustainable groundwater potential zone using remote sensing and GIS. $6^{\text {th }}$ International Colloquium on Signal Processing and Its Applications, Mallaca, Malaysia, 6 pp.

23. Onder, H. and M. Yilmaz. 2005. Underground Dams, A tool of sustainable development and management of groundwater resources, European Water publications, 11(12): 35-45.

24. Ouerdachi, B., B. Hafsi, B. Tayeb. 2010. Modeling of underground dams, Application to planning in the semi-arid areas (Biskra, Algeria), Energy Procedia, Elsevier publications, 18: 426-437. 
צr مكان يابى مناطق مستعد احداث سد زيرزمينى با استفاده از منطق فازى و بولين در مناطق مركزى استان اردبيل ..

25. Pirmoradi, R., M. Nakhaei and F. Asadian. 2011. Determining suitable areas for underground dam construction using GIS and AHP, Case study: Malayer plain in Hamedan province. Natural Geography, 3(8): 51-66 (In Persian).

26. Rahman, M.A., B. Rusteberg, R.C. Gogu, J.L. Ferreira and M. Sauter. 2012. A new spatial multicriteria decision support tool for site selection for implementation of managed aquifer recharge. Environmental Management, 99: 61-75.

27. Raju, J., J. Reddy and M. Truski. 2006. Subsurface dams to harvest rainwater, a case study of the swarnamakhi river basin, Southern India, Hydrogeology, 14(4): 526-531.

28. Razavi, S. and J. Samani. 2016. Evaluating water management strategies in watersheds by new hybrid Fuzzy Analytical Network Process methods. Hydrology, 534: 364-376.

29. Saadati, H. 2012. GIS and remote sensing, Islamic Azad University Ardabil Press, 431 pp (In Persian).

30. Shenkut, M. 1999. Design of Subsurface Dam for BoriVillage, AddisAbaba, Ethiopia, 21 pp.

31. Shenkut, M. 2001. Rainwater harvesting with subsurface and sand dams, 10th international rainwater catchment systems conference, section2: rainwater catchment in humid and arid regions, Mannheim, Germany, $6 \mathrm{pp}$.

32. Soleimani, S., M. Nikoodel, A. Oroumiey and H. Bahrami. 2009. Suitable site selection of underground dam Using RS and GIS, Third Conference of Iran Water Resources Management, Tabriz University, (In Persian).

33. Tabatabei Yazdi, J. and S. Nabipey. 2004. Underground water dams for small-scale water supply. Soil Conservation and Watershed Management Research Institute. Tehran, Iran, pp. 63, (In Persian).

34. Trinh, K. 2016. Effective Boolean dynamics analysis to identify functionally important genes in large-scale signaling network. Biosystems, 137: 64-72.

35. Updegrove, A., N. Wilson and S. Shadden. 2016. Boolean and smoothing of discrete polygonal surfaces, Journal of Advances in Engineering, 95(3): 16-27.

36. Yousefi, S., H. Mohammadzadeh and M. Akbari. 2014. An Evaluation of Groundwater Potential Zones Using Combined Fuzzy-AHP Method and GIS/RS Technologies. Water Resources and Development, 2(4): 124-141 (In Persian).

37. Zolnavar, A. and M. Ahmadi. 2003. Provides a method for designing and implementing underground dam body using plastic concrete. $6^{\text {th }}$ Conference on civil engineering. Isfahan University, pp. 126, (In Persian). 


\title{
Determination of Suitable Areas for Underground Dam Construction Using Boolean and Fuzzy Logics in Central Areas of Ardebil Province
}

\author{
Abazar Esmali ${ }^{1}$, Mohammad Golshan ${ }^{2}$ and Keyvan Khorrami ${ }^{3}$ \\ 1- Associate Professor, Faculty of Agriculture and Natural Resources, University of Mohaghegh Ardabili, Ardabil \\ (Corresponding Author: abazar.esmali@gmail.com) \\ 2- Ph.D., Natural Resources and Watershed Management Office, Astara, Guilan \\ 3- Ph.D. Student, Watershed Management Engineering Department, Urmia University, Urmia \\ Received: June 15, 2018 \\ Accepted: January 16, 2019

\begin{abstract}
In the arid and semi-arid areas rainfall have considerable changes in terms of time and amount, and that make the water resource management an vital issue. In this research, both Boolean and Fuzzy logic were used for identifying the potentiality suitable areas for construction of underground dams. The study area is located in the central region of Ardabil province with $7461 \mathrm{~km} 2$ area and semi-arid climate. For this purpose, were used many criteria consist of topography, geology, land use, geomorphology, water quality and quantity, depth of alluvial, and channels ranking. In the Boolean logic method, after preparing the related criteria, suitable and unsuitable areas were determined in two classes 0 and 1 that were combined using AND operator. In the Fuzzy logic method, the criteria were prepared in many classes and scored from 0 to 1 regarding previous researches and area conditions, then the criteria were combined with Fuzzy gamma operator. There is a good accordance between used criteria and combined maps that obtained from two methods. Overall central area and part of southwest and northern area determined as suitable locations for construction of underground dams. Results of Fuzzy logic showed that in the study area, the streams with 3 rank and deep alluvial areas have a high potentiality for underground dams' construction. Therefore, these areas should be considered as the suitable areas for underground dams.
\end{abstract}

Keywords: Alluvial, Geology, Hydrologic factors, Water resource 